\title{
Post-operative analgesia of $2 \%$ lignocaine with or without magnesium sulfate for inferior alveolar nerve block in symptomatic mandibular molars - a randomized double blind controlled clinical trial
}

\author{
Charanya Chandrasekaran', Vijay Amirtharaj $L^{2}$, Mahalaxmi Sekarr ${ }^{2}$, Mary Nancy $S^{2}$ \\ ${ }^{1}$ Tagore Dental College and Hospital, Rathinamangalam, Chennai, India \\ ${ }^{2}$ SRM Dental College, Ramapuram, Chennai, India
}

\begin{abstract}
Background: Single inferior alveolar nerve block is ineffective in achieving adequate pulpal anesthesia in 30-80\% of patients due to anatomical variations, local tissue $\mathrm{pH}$, central sensitization, and several factors. Various supplementary techniques and combination of adjuvants with lignocaine are used to overcome these failures. Magnesium sulfate $\left(\mathrm{MgSO}_{4}\right)$, one such adjuvant, acts at the $\mathrm{N}$-methyl-D-aspartate glutamate receptor resulting in effective anesthesia. The aim of this prospective, randomized, double-blind, clinical controlled trial was to evaluate the onset, anesthetic efficacy, duration and post-operative analgesia of $2 \%$ lignocaine with and without the addition of $\mathrm{MgSO}_{4}$ in patients with symptomatic irreversible pulpitis and apical periodontitis.

Methods: Fourty-two patients were randomly divided into three groups: $2 \%$ lignocaine (group 1) and 2\% lignocaine with $\mathrm{MgSO}_{4}(75 \mathrm{mg})$ and $(150 \mathrm{mg})$ in groups 2 and 3, respectively. Pre-operative vitals and Heft Parker-Visual Analogue Scale (HP-VAS) pain scores were recorded. The onset of anesthesia, anesthetic efficacy, and duration of anesthesia were evaluated post administration of the local anesthetic solution. The post-operative analgesia was examined at intervals of $2,6,12,24$, and $48 \mathrm{~h}$.

Results: Administration of $150 \mathrm{mg} \mathrm{MgSO}_{4}$ hastens the onset of anesthesia $(1.29 \mathrm{~min})$ and produces better anesthetic efficacy (3.29 HP-VAS) compared to group 2 (2.07 min and 9.14 HP-VAS) and group 1 (3.29 min and 35.79 HP-VAS), respectively. The duration of anesthesia was significantly higher in group 3 (247.07 min) compared to that of groups 2 and 1 (190 $\mathrm{min}$ and $110.21 \mathrm{~min})$ with $\mathrm{P}<0.05$.

Conclusion: Combining $75 \mathrm{mg}$ or $150 \mathrm{mg}$ of $\mathrm{MgSO}_{4}$ with lignocaine is more effective than $2 \%$ lignocaine and $75 \mathrm{mg}$ of $\mathrm{MgSO}_{4}$ is adequate for endodontic procedures.
\end{abstract}

Keywords: Anesthetic efficacy; Duration; Inferior Alveolar Nerve; Lignocaine; Magnesium Sulfate; Onset; Postoperative Pain.

This is an Open Access article distributed under the terms of the Creative Commons Attribution Non-Commercial License (http://creativecommons.org/licenses/by-nc/4.0/) which permits unrestricted non-commercial use, distribution, and reproduction in any medium, provided the original work is properly cited.

\section{INTRODUCTION}

Achieving profound pulpal anesthesia during root canal treatment is very important in endodontics [1]. The success rate of the inferior alveolar nerve block (IANB) routinely used to anesthetize the mandibular's posterior region is only approximately $75-90 \%$ due to the large surface area covered by the inferior alveolar nerve [2]. However, it becomes inadequate in inflamed tissues, where the success rate is approximately $30-80 \%$ in patients with symptomatic irreversible pulpitis, which is

Received: February 3, 2020 • Revised: April 21, 2020 - Accepted: June 6, 2020

Corresponding Author: Charanya Chandrasekaran, Senior Lecturer, Tagore Dental College, Rathinamangalam, Chennai - 600127, India

Tel: +9791146861 E-mail- charanya1711@gmail.com

Copyright@ 2020 Journal of Dental Anesthesia and Pain Medicine 
challenging [3].

This lower success rate of local anesthetics (LA) could be attributed to anatomical variations, local tissue $\mathrm{pH}$, acute tachyphylaxis, effect of nociceptors, central sensitization, psychological reasons, and more [1]. To overcome such failures, various supplementary anesthetic techniques such as intraligamentary, intraosseous, and intrapulpal are used routinely [4]. However, the additional needle prick may have a negative effect on the patient's psychology. Instead, an adjuvant such as epinephrine, mannitol, or ketorolac added to the LA produces synergistic anesthetic effect [5]. A thorough review of the literature showed that only limited drugs that are potent inhibitors of N-methyl D-aspartate (NMDA) glutamate receptor are available that provide central sensitization and block pain perception.

Magnesium sulphate $\left(\mathrm{MgSO}_{4}\right)$ is used as an adjuvant in various fields of general anesthesia (GA), as intraoperative analgesics in obstetrics, in cardiovascular surgeries, in cases of epilepsy, etc. [6]. Narang et al. (2008) evaluated the use of $\mathrm{MgSO}_{4}$ added to lignocaine as a single dose in intravenous regional anesthesia for upper limb surgery and concluded that $\mathrm{MgSO}_{4}$ had better anesthetic and analgesic effects [7]. In dentistry, Shetty $\mathrm{KP}$ et al. (2016) showed that administering pre-injection of $\mathrm{MgSO}_{4}$ before giving IANB increased the anesthetic efficacy [8]. However, this requires two needle pricks for the patient, which may be a psychological deterrent. There are no clinical studies evaluating $\mathrm{MgSO}_{4}$ combined with lignocaine as a single dose. Hence, the aim of our prospective randomized, double-blind, controlled clinical trial was to combine $\mathrm{MgSO}_{4}$ with $2 \%$ lignocaine in two different concentrations ( $75 \mathrm{mg}$ and $150 \mathrm{mg}$ ) to evaluate the onset, duration and anesthetic efficacy, and postoperative analgesia during routine root canal treatment in patients with symptomatic irreversible pulpitis and symptomatic apical periodontitis. The null hypothesis proposed was that the addition of $\mathrm{MgSO}_{4}$ to $2 \% \mathrm{LA}$ will not have any effect on the above mentioned parameters.

\section{METHODS}

The study protocol was presented to and ethical approval was obtained from the Institutional Review Board and Ethical Committee of the SRM Dental College, Ramapuram, Tamil Nadu, India. The trial was registered with the Clinical Trials Registry of India before commencement of the trial. (CTRI/2018/01/011569) (September 2016 to 2019). The study consisted of three groups: $1.5 \mathrm{ml}$ of $2 \%$ LA only (Loxicard $2 \% ; 50 \mathrm{ml}$; Neon; Mfg. Lic. No. KD/2632- A, Mumbai, India) (group 1), $1.5 \mathrm{ml}$ of $2 \%$ LA with $0.15 \mathrm{ml}$ of $\mathrm{MgSO}_{4}$ (Magneon, Neon Laboratories, Mumbai, India) containing an osmolar concentration of approximately $4.060 \mathrm{mosmol} / \mathrm{ml}$ that is equivalent to $75 \mathrm{mg}$ of $\mathrm{MgSO}_{4}$ (group 2). Group 3 consisted of $1.5 \mathrm{ml}$ of $2 \% \mathrm{LA}$ with $0.3 \mathrm{ml}$ of $\mathrm{MgSO}_{4}$ equivalent to $150 \mathrm{mg}$ of $\mathrm{MgSO}_{4}$. Patients classified under the American Society of Anesthesiologists (ASA) categories I and II, within the age groups of 20 to 60 years were screened in the study. After thorough clinical and radiographic examination along with sensitivity tests, those who were diagnosed with symptomatic irreversible pulpitis and symptomatic apical periodontitis of mandibular molar teeth were recruited into the study. Study protocol was explained to the patients and informed consent was obtained from those willing to participate. The maximum dosage used here is lesser than the adverse range and is safer for endodontic procedures as adverse drug reactions occur only when the serum magnesium level exceeds $6-7 \mathrm{mmol} / \mathrm{kg}$.

Patients with pain of moderate-to-severe intensity (American association of endodontists guidelines) (85 to 170 Heft Parker-Visual Analogue Scale (HP-VAS) pain score) in the mandibular posterior teeth and those who were able to understand the pain scale and respond immediately to electric pulp testing were included in the study. Exclusion criteria included ASA category III and above, patients with any prior medications, those allergic to LA, pregnant, and lactating women.

This study was designed as a randomized controlled 
trial with the evaluation of post-operative analgesia as the primary outcome and onset, duration and anesthetic efficacy as secondary outcome measures. Based on these primary and secondary outcomes, a non-blind pilot study was conducted to determine the sample size using six patients in each group. On basis of the results of the pilot study and individual power calculation, 11 subjects per group $(\mathrm{N}=33)$ would provide a minimum of $90 \%$ power in all categories. Considering $20 \%$ drop-outs, the total sample size was calculated to be 14 per group. The recruited 42 patients were randomly allocated to three groups using block randomization (www.randomization.org). The experimental solutions were freshly prepared by an anesthesiologist (operator 1) who maintained the master coded list of the patients with the respective solutions. The patients, endodontist (operator 2) who performed the treatment, and evaluator (operator 3) who recorded the pre and post-operative parameters were blinded to the anesthetic solution used.

Before starting the procedure, the evaluator recorded the baseline pain values using the HP-VAS pain score. The endodontist then injected the coded anesthetic solution prepared by the anesthesiologist, on the landmark of corresponding operating IANB quadrant on the affected site. After negative aspiration, the local anesthetic solution was slowly deposited at the rate of $1.5 \mathrm{ml}$ over 60 seconds. The Electric pulp tester (EPT) is a device to determine the vitality of the pulp. The onset of anesthesia was evaluated by EPT for every $1 \mathrm{~min}$ until the corresponding vital tooth stopped responding.

Root canal treatment was initiated and access cavity preparation was done under rubber dam isolation. The anesthetic efficacy was calculated using HP-VAS pain score on placement of the first 10 size $\mathrm{K}$ file (Mani Inc., Japan). Cleaning and shaping of the root canal system was performed subsequently, sterile cotton pellet was placed, and closed dressing given using Cavit-G (3M ESPE, Germany). The duration of anesthesia was evaluated every 15 min using EPT till the adjacent normal tooth responded on the working side. In this study, none of the patients experienced pain during the procedure and

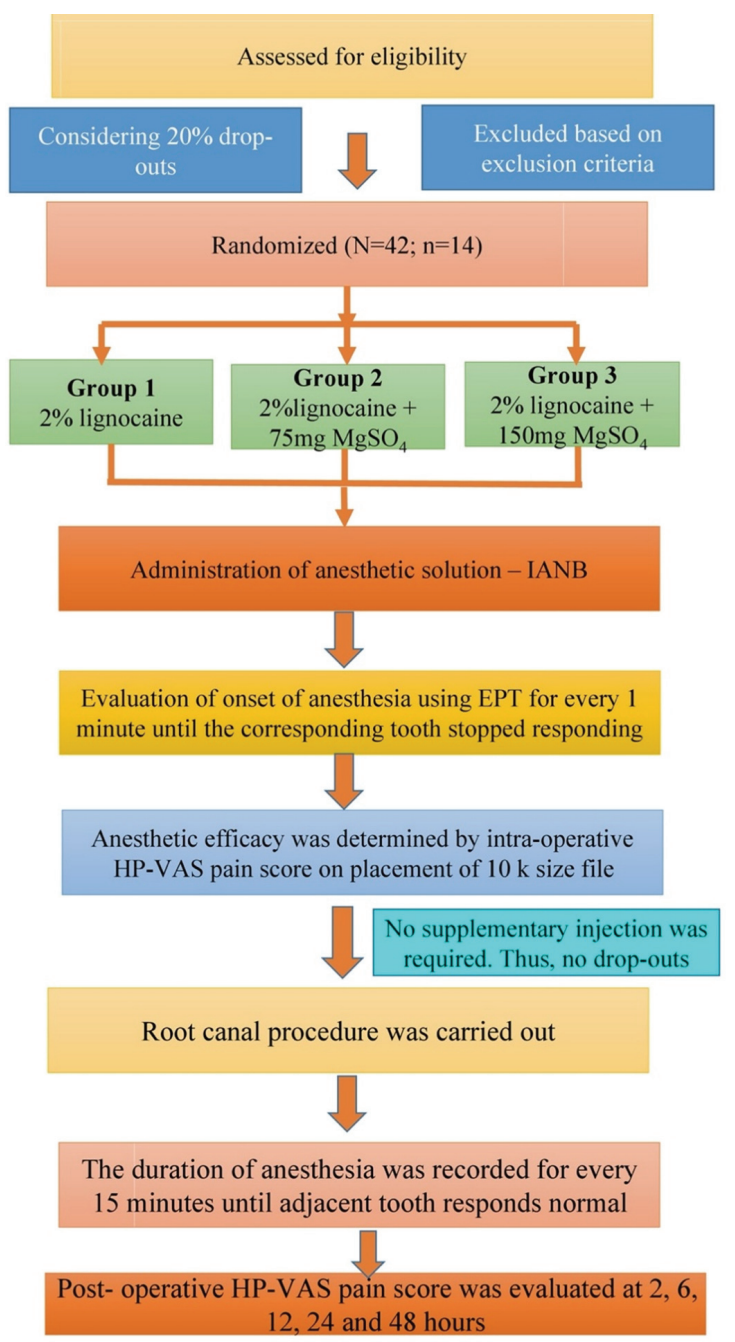

Fig. 1. CONSORT flowchart

thus no other supplementary injection was required in both groups. Post-operative analgesic efficacy was assessed up to $2 \mathrm{~h}$ after the procedure at the operating site. Subsequently, the patient was handed a HP-VAS pain scale and was requested to respond to our telephonic evaluation at 6, 12, 24, and $48 \mathrm{~h}$. Figure 1 shows the Consort flow diagram of this randomized controlled clinical trial. Post-operative instructions were given to all the patients along with the prescription of an antiinflammatory drug, to be consumed only if pain arises. On the subsequent visit, the endodontic therapy was completed.

\section{Statistical analysis}

All the data were tabulated in excel sheet. Statistical 
Table 1. Demographic data and pre-operative vital signs

\begin{tabular}{|c|c|c|c|c|}
\hline & Group 1 & Group 2 & Group 3 & Stat. analysis \\
\hline Pulse rate & $70.43+/-6.123$ & $68.64+/-5.358$ & $73.57+/-5.801$ & $P>0.05$ \\
\hline Peripheral Oxygen saturation level $\left(\mathrm{SpO}_{2}\right)$ & $95.36+/-2.763$ & $95.21+/-3.142$ & $94.93+/-4.104$ & $P>0.05$ \\
\hline Blood pressure & $97.5+/-5.801$ & $97.14+/-5.789$ & $99.29+/-2.673$ & $P>0.05$ \\
\hline Gender distribution (M:F) & $6: 08$ & 8:06 & $4: 10$ & \\
\hline Pre-operative HP-VAS pain score & $124.57+/-24.422$ & $122.57+/-14.064$ & $122.64+/-18.177$ & $P>0.05$ \\
\hline
\end{tabular}

EPT, electric pulp tester; HP-VAS, Heft Parker-Visual Analogue Scale

Table 2. Onset, duration and anesthetic efficacy of the 3 groups

\begin{tabular}{ccrc}
\hline Groups & Onset (Mins) & Duration (Mins) & $\begin{array}{c}\text { Anesthetic efficacy } \\
\text { (HP-VAS Pain score) }\end{array}$ \\
\hline Group 1 & $3.29+/-0.994^{\mathrm{a}}$ & $110.21+/-37.559^{\mathrm{a}}$ & $35.79+/-33.598^{\mathrm{a}}$ \\
Group 2 & $2.07+/-0.73^{\mathrm{b}}$ & $190+/-37.250^{\mathrm{b}}$ & $9.14+/-13.132^{\mathrm{b}}$ \\
Group 3 & $1.29+/-0.611^{\mathrm{b}}$ & $247.07+/-26.339^{\mathrm{c}}$ & $3.29+/-8.352^{\mathrm{b}}$ \\
\hline
\end{tabular}

Note: Different alphabetical superscripts indicate statistical significance between the groups $(P<0.05)$

HP-VAS, Heft Parker-Visual Analogue Scale

Table 3. Comparison of post-operative analgesic efficacy at 2, 6, 12, 24, and $48 \mathrm{~h}$ intervals

\begin{tabular}{ccccccc}
\hline Groups / Hours & 2 & 6 & 12 & 24 & 48 \\
\hline Group 1 & $50.21+/-51.54^{\mathrm{a}}$ & $31.79+/-34.77^{\mathrm{a}}$ & $21.64+/-25.25^{\mathrm{a}}$ & $20.14+/-18.85^{\mathrm{a}}$ & $14.64+/-17.22^{\mathrm{a}}$ \\
Group 2 & $25.36+/-35.78^{\mathrm{a}}$ & $24.64+/-35.89^{\mathrm{a}}$ & $13.64+/-32.62^{\mathrm{a}, \mathrm{b}}$ & $4.21+/-11.01^{\mathrm{b}}$ & $1.64+/-6.14^{\mathrm{b}}$ \\
Group 3 & $31.86+/-42.88^{\mathrm{a}}$ & $11.93+/-24.15^{\mathrm{a}}$ & $1.63+/-6.14^{\mathrm{b}}$ & $0.00^{\mathrm{b}}$ & $0.00^{\mathrm{b}}$ \\
\hline
\end{tabular}

Note: Different alphabetical superscripts indicate statistical significance between the groups $(P<0.05)$

analysis was performed with $\mathrm{R}$ statistical software (version 3.5.1). Since most of the data were ordinal in nature and non-normal in distribution as observed by the Shapiro Wilk test, non-parametric test was used to test the statistical significance within and between the groups. Kruskal Wallis and Dunn Post hoc tests were employed to determine the statistical significance in onset, duration, and efficacy of anesthesia among the three groups. Post-operative analgesia at 2, 6, 12, 24, and $48 \mathrm{~h}$ within the group was analyzed using Friedman test followed by Dunn post hoc test. Multiple comparisons were made at a significance level of $\mathrm{P}<0.05,95 \%$ confidence interval, and power set at $90 \%$.

\section{RESULTS}

The patients' demographic data is shown in Table 1 . The patients were equally distributed between the groups and show no significant difference. The mean and standard deviation of onset, duration and anesthetic efficacy of the three groups are mentioned in Table 2. Both experimental groups showed a significant difference in the onset, duration, and anesthetic efficacy compared to the control group. There was no significant difference between groups 2 and 3 in terms of the onset and anesthetic efficacy, but a significant difference was observed in the duration of anesthesia.

The mean HP-VAS scores of post-operative analgesic efficacy at different time points for all the three groups are given in Table 3. Friedman non-parametric test showed significant reduction in pain from the $12^{\text {th }}$ hour in the experimental groups.

\section{DISCUSSION}

Pain is a complex and multidimensional phenomenon 
that requires comprehensive and ongoing assessment for an effective management. In the peripheral nervous system, the nociceptive message is transmitted from the periphery to the central nervous system via the axon of primary afferent nociceptors. There is a correlation between the intensity of stimulus and frequency of nociceptor discharge. In symptomatic irreversible pulpitis, voltage gated sodium channels are responsible for the transmission of pain. These are stimulated under physiological conditions by the excitable cells causing depolarization of the neurons and activation of the sodium channels subsequently transmitting the pain signals to the brain. Substances such as bradykinin and prostaglandin E2 are released from the inflamed tissue to activate or sensitize the nociceptor at the neurons. In case of pulpal pain, the sensitization of pulpal nociceptors exhibits an increased resistance to local anesthetics. Inflammation also changes the synthesis of several neuropeptides and thus influences at the nociceptor level $[9,10]$. A probable assumption for local anesthetic failure during inflammation is an increase in the anesthetic-resistant subpopulation of sodium channels [1].

In this study, patients diagnosed as symptomatic irreversible pulpitis with symptomatic apical periodontitis were included because inflamed pulp causes pain, but once the inflamed pulp is treated, the pain progressively subsides. Whereas, in case of symptomatic apical periodontitis, the inflammatory mediators that are present increase the neuropeptides such as prostaglandins E2 and bradykinin and can cause exaggerated central sensitization even in the presence of a small stimulus. This results in more post-operative pain [1].

For IANB, $1.5 \mathrm{ml}$ of $2 \%$ lignocaine without methylparaben and adrenaline was used in this study. This is to standardize the anesthetic solution, rule out hypersensitivity reaction in patients, avoid any interaction between methylparaben and $\mathrm{MgSO}_{4}$, and avoid the influence of adrenaline on the heart rate and blood pressure, respectively $[11,12]$. Literature states that even $1.0 \mathrm{ml}$ of $2 \%$ lignocaine is an effective volume for obtaining clinical success in IANB [13]. Usual regimens of $\mathrm{MgSO}_{4}$ administered as intravenous injection were a dose of 30-50 mg/ $/ \mathrm{kg}$ followed by a continuous dose of 6-20 mg/kg/h till the end of surgery. According to the literature, $150 \mathrm{mg}$ is the lowest concentration used in regional anesthesia for plexus block [14]. Since the inferior alveolar nerve is a peripheral nerve without a multiple plexus of nerves, a smaller dose of $75 \mathrm{mg}$ was also chosen along with $150 \mathrm{mg}$ of $\mathrm{MgSO}_{4}$ in this randomized controlled clinical trial. The experimental anesthetic solution was freshly mixed to retain the chemical properties of the drug. However, Houlihan S et al. earlier observed that freshly mixed anesthetic solution showed no precipitation for up to 168 days when stored at $25^{\circ} \mathrm{C}$ and $40^{\circ} \mathrm{C}$ [15].

Though there are various forms of IANB techniques, the conventional form of injecting the solution is still considered to be effective and a gold standard. Since IANB has a failure rate of approximately $0-48.6 \%$, a well experienced single operator administered the block for maximum effectiveness and standardization [16].

There was no significant difference in the demographic data and pre-operative vitals, indicating a random and an even distribution of subjects between the three groups (Table 1). This is in accordance to the statement of Wolff (1940) and Mumford (1965) who stated that the perception of pain is independent of age and sex [17,18].

The results of this study show that $150 \mathrm{mg}$ of $\mathrm{MgSO}_{4}$ when added to lignocaine provided faster and longer duration of anesthesia, maximum anesthetic efficacy, and better post-operative analgesia as compared to $2 \%$ LA. Hence, the null hypothesis was rejected. In addition, 75 $\mathrm{mg}$ of $\mathrm{MgSO}_{4}$ also showed better results comparable to those of $150 \mathrm{mg} \mathrm{MgSO}$, though there was a significant difference between the 2 experimental groups in terms of the anesthetic efficacy.

In a study by Koinig et al. (1998), peri-operative administration of $50 \mathrm{mg} / \mathrm{kg} \mathrm{MgSO} 4$ reduced the analgesic requirements both intra- and post-operatively [19]. In addition, it was proved that adding $50 \mathrm{mg} / 100 \mathrm{mg}$ of intrathecal $\mathrm{MgSO}_{4}$ had a significant increase in the duration of anesthesia and analgesia that had a dose 
related linear relationship [20].

Magnesium is a natural physiological calcium antagonist at different voltage gated channels, which has an important role to play in anti-nociception. The addition of $\mathrm{Mg}^{2+}$ blunts NMDA receptor activation, which obstructs the excitatory postsynaptic currents and diminishes the stimulation of C-fibers. $\mathrm{MgSO}_{4}$ abolishes hypersensitization by obstructing the activation of NMDA receptor in the dorsal horn of the brain via the amino acid transmitters, notably glutamate and aspartate, thus reducing central sensitization [21]. Magnesium has analgesic effects by itself and it also enhances the actions of established analgesics when used as an adjuvant [22].

This study also proves that the addition of $\mathrm{MgSO}_{4}$ to $2 \%$ LA has a dose dependent increase in the onset, duration, anesthetic efficacy, and post-operative analgesia. From the results of the study, we can extrapolate that $75 \mathrm{mg} \mathrm{MgSO}_{4}$ is sufficient in endodontics, since the duration of anesthesia with this group was found to be $190+/-37.250$, which is more than adequate for the endodontic procedure to be completed.

It was further observed that the patients of the control group had lesser pain relief at 2 and $6 \mathrm{~h}$ compared to groups 2 and 3, though not statistically significant. Siqueira JF and Barnett F stated that the highest peak of post-operative pain was present at the $6^{\text {th }}$ hour due to the action of the inflammatory mediators as a result of the local immune response [23]. It can be inferred that action of $\mathrm{MgSO}_{4}$ on the NMDA receptor and calcium channel blockers progressively reduced the postoperative pain and also proved to be effective at the $6^{\text {th }}$ hour time point in Table $3 . \mathrm{MgSO}_{4}$ in both concentrations proved to be effective in post-operative analgesia at 12 , 24 , and $48 \mathrm{~h}$ with significant reduction in pain compared to group 1 .

However, contradictory results were reported in the literature by few authors who showed that $\mathrm{MgSO}_{4}$ has limited or no effect on post-operative pain in patients undergoing abdominal hysterectomy and caesarean delivery $[24,25]$. Tramer MR and Glynn CJ also observed that the pre-treatment of $\mathrm{MgSO}_{4}$ for ambulatory ilioinguinal hernia repair or operation of varicose vein had no effect on postoperative analgesia because of the heterogeneous populations and dose variation [26]. In our study, the pre-serum values of $\mathrm{Mg}^{2+}$ was not taken into consideration, although they may have an influence on the results.

To conclude, this clinical trial shows that both $75 \mathrm{mg}$ and $150 \mathrm{mg}$ of $\mathrm{MgSO}_{4}$ in combination with LA are more effective than $2 \%$ LA alone. The anesthetic duration achieved with $75 \mathrm{mg}$ of $\mathrm{MgSO}_{4}$ is more than adequate for most of the dental procedures. Pertaining to the post-operative analgesia, both $75 \mathrm{mg}$ and $150 \mathrm{mg}$ did not have significant difference from $24 \mathrm{~h}$ onwards. Hence, considering the dental procedure that requires only half the duration compared to general surgery, a lower concentration or dose should be more than adequate for most dental procedures.

\section{AUTHOR ORCIDS}

Charanya Chandrasekaran: https://orcid.org/0000-0001-6795-6064

Vijay Amirtharaj L: https://orcid.org/0000-0002-4355-8296

Mahalaxmi Sekar: https://orcid.org/0000-0002-7159-8180

Mary Nancy S: https://orcid.org/0000-0003-4756-5650

AUTHOR CONIRIBUIIONS

Charanya Chandrasekaran: Conceptualization, Data curation, Formal analysis, Funding acquisition, Investigation, Methodology, Resources, Software, Supervision, Validation, Visualization, Writing - original draft, Writing - review \& editing

Vijay Amirtharaj L: Conceptualization, Formal analysis, Project administration, Supervision, Validation, Writing - review \& editing

Mahalaxmi Sekar: Conceptualization, Formal analysis, Supervision, Validation, Writing - review \& editing

Mary Nancy S: Investigation, Supervision, Validation

DECLARATION OF INTERESTS: The authors declare that they have no conflict of interest

\section{REFERENCES}

1. Hargreaves KM, Keiser K. Local anesthetic failure in 
endodontics : Mechanisms and Management. Endodontic Topics 2002; 1: 26-39.

2. Malamed SF. Handbook of local anesthesia. 3rd ed. Philadelphia, Elsevier's Health Sciences. 1990, pp 1-332.

3. Nusstein J, Reader A, Nist R, Beck M, Meyers WJ. Anesthetic efficacy of the supplemental intraosseous injection of $2 \%$ lidocaine with 1:100,000 epinephrine in irreversible pulpitis. J Endod 1998; 24: 487-91.

4. Boopathi T, Sebeena M, Sivakumar K, Harikaran J, Karthick K, Raj A. Supplemental pulpal anesthesia for mandibular teeth. J Pharm Bioallied Sci 2013; 5(Suppl 1): S103-8.

5. Swain A, Nag DS, Sahu S, Samaddar DP. Adjuvants to local anesthetics: Current understanding and future trends. World J Clin Cases 2017; 5: 307-23.

6. Ryu JH, Kang MH, Park KS, Do SH. Effects of magnesium sulphate on intraoperative anaesthetic requirements and postoperative analgesia in gynaecology patients receiving total intravenous anaesthesia. Br J Anaesth 2008; 100: 397-403.

7. Narang S, Dali JS, Agarwal M, Garg R. Evaluation of the efficacy of magnesium sulphate as an adjuvant to lignocaine for intravenous regional anaesthesia for upper limb surgery. Anesth Intensive Care 2008; 36: 840-4.

8. Shetty KP, Satish SV, Kilaru KR, Sardar P, Luke AM. Comparison of anesthetic efficacy between lidocaine with and without magnesium sulfate USP $50 \%$ for inferior alveolar nerve blocks in patients with symptomatic irreversible pulpitis. J Endod 2015; 41: 431-3.

9. Catterall WA. From ionic currents to molecular mechanisms:the structure and function of voltage-gated sodium channels. Neuron 2000; 26: 13-25.

10. Hille B. Ion Channels of Excitable Membrane. 1st ed. Sunderland, MA, USA, Sinauer Assoc Publishers. 1984, pp 58-75.

11. Larson CE. Methylparaben-an overlooked cause of local anesthetic hypersensitivity. Anesth Prog 1977; 24: 72-4.

12. Ketabi M, Shamami MS, Alaie M, Shamami MS. Influence of local anesthetics with or without epinephrine $1 / 80000$ on blood pressure and heart rate: A randomized doubleblind experimental clinical trial. Dent Res J (Isfahan) 2012;
9: $437-40$.

13. Rood JP. The nerve supply of the mandibular incisor region. Br Dent J 1977; 143: 227-30.

14. Do SH. Magnesium : a versatile drug for anesthesiologists. Korean J Anesthesiol 2013; 65: 4-8.

15. Houlihan S, Decarie D, Benes C, Cleve R, Vidler M, Magee LA. Magnocaine: Physical Compatibility and Chemical Stability of Magnesium Sulphate and Lidocaine Hydrochloride in Prefilled Syringes. J Obstet Gynaecol Can 2016; 38: 936-44.

16. Lin S, Wigler R, Huber R, Kaufman AY. Anaesthetic efficacy of intraligamentary injection techniques on mandibular molars diagnosed with asymptomatic irreversible pulpitis: A retrospective study. Aust Endod J 2017; 43: 34-7.

17. Wolff HG, Hardy JD, Goodell H. Studies on pain. Measurement of the effect of morpine, codeine and other opiates on the pain threshold and analysis of their relation to the pain experience. J Clin Invest 1940; 19: 659-80.

18. Mumford JM. Pain perception threshold and adaptation of normal human teeth. Arch Oral Biol 1965; 10: 957-68.

19. Koinig H, Wallner T, Marhofer P, Andel H, Horauf K, Mayer N. Magnesium sulfate reduces intra- and postoperative analgesic requirements. Anesth Analg 1998; 87: 206-10.

20. Jaiswal R, Bansal T, Kothari S, Ahlawat G. The effect of adding magnesium sulphate to bupivacaine for spinal anaesthesia: a randomised, double-blind trial in patients undergoing lower limb orthopaedic surgery. Int J Pharm Pharm Sci 2013: 5: 179-82.

21. Dubé L, Granry JC. The therapeutic use of magnesium in anesthesiology, intensive care and emergency medicine: a review. Can J Anaesth 2003; 50: 732-46.

22. Tramer MR, Schneider J, Marti RA, Rifat K. Role of magnesium sulfate in postoperative analgesia. Anesthesiology 1996; 84: 340-7.

23. Siqueira JF, Barnett F. Interappointment pain: mechanisms, diagnosis, and treatment. Endod Top 2004: 7: 93-109.

24. Ko SH, Lim HR, Kim DC, Han YJ, Choe H, Song HS. Magnesium sulfate does not reduce postoperative analgesic requirements. Anesthesiology 2001; 95: 640-6. 
25. Paech MJ, Magann EF, Doherty DA, Verity LJ, Newnham JP. Does magnesium sulfate reduce the short- and long-term requirements for pain relief after caesarean delivery? A double-blind placebo-controlled trial. Am J Obstet Gynecol 2006; 194: 1596-602.
26. Tramer MR, Glynn CJ. An evaluationof a single dose of magnesium to supplement analgesia after ambulatory surgery: randomized controlled trial. Anesth Analg 2007; 104: 1374-9. 